\title{
EXPERIMENTAL AND NUMERICAL INVESTIGATION ON SPECIMEN GEOMETRY EFFECT ON THE CTOD VALUE FOR VL-E36 SHIPBUILDING STEEL
}

Jakub Kowalski

Gdansk University of Technology, Poland

*Corresponding author: jakkowall@pg.edu.pl(J. Kowalski)

\begin{abstract}
There are special cases in the marine industry, where additional material tests, such as the fracture toughness test, must be performed. Additional fracture toughness tests, such as CTOD (Crack Tip Opening Displacement), are typically performed on three-point bend specimens. The dimension that defines all the specimen dimensions is the thickness of the material to be tested. It is recommended by classification societies (e.g. DNVGL) to test specimens that are twice as high as the material thickness. The width determines the length and, therefore, the weight of the specimen which, for a $100 \mathrm{~mm}$ plate is over $140 \mathrm{~kg}$. Current ASTM E1820, BS7448-1 and ISO 12135 testing standards also allow for proportions other than those recommended. This results in a much smaller test piece. Reducing the specimen size allows the testing machine to achieve lower forces than a specimen with a width to thickness ratio of two. This paper presents the effect of changing the specimen geometry on CTOD test results. Research was performed for specimens with a height to thickness ratio of one and two. Abaqus software was used for numerical calculations. The numerical results were, at selected points, verified experimentally.
\end{abstract}

Keywords: CTOD,Fracture toughness,Ductility,FEM,Abaqus

\section{INTRODUCTION}

Contemporary research on modern ship and offshore structures and their production methods is carried out in many fields. One of the branches of study is the technology of joining ship's plates by welding. The issues raised include the influence of non-typical welding processes on material properties [1]. A similar issue (related to post-welding processes), straightening is the effect of straightening processes on the corrosion resistance and mechanical properties of austenitic steels [2]. Another group of research is the study of phenomena, carried out on models. In this group of studies, we can find publications on the working mechanisms and failure of structures made of composites [3], behaviour of stiffened panels in ultimate load conditions [4] or the influence of corrosion factors on mechanical properties [5]. Moreover, the fracture toughness of structures is a frequent topic of research and this is the intent of this paper.

The basic criterion for the assessment of ductility of steel plates used for ship hulls is absorbed energy determined by impact using the Charpy test method. Depending on the steel category, the test is performed at different temperatures. Energy absorbed during impact is a quantitative parameter; a value higher than the criterion value indicates the suitability of the material batch for hull construction. The result does not give information about the nature of the fracture. The criterion, based on the Charpy method, is sufficient in the vast majority of cases. Thick plates, particularly plates thicker 
than $50 \mathrm{~mm}$, with higher yield points (equal or higher than $315 \mathrm{~N} / \mathrm{mm}^{2}$ ) and high strength (yield point from 420 to 960 $\mathrm{N} / \mathrm{mm}^{2}$ ) are an exception. In members of this thickness, the predominant mode of operation is the plane strain state. In addition, high stress levels are allowed, due to the high strength of steel. In such cases, the standard Charpy test, performed on standard size specimens $(10 \times 10 \times 55 \mathrm{~mm})$ may prove to be unreliable. For this reason, for materials used in safety-critical structures, additional tests are performed based on the principles of fracture mechanics. One such test, most often performed in shipbuilding and the offshore industry is the Crack Tip Opening Displacement Test (CTOD).

Fracture mechanics describes the ductility of a material, unlike the Charpy test, not only quantitatively but also qualitatively. Current testing standards specify three quantities that can be determined experimentally: $\mathrm{K}_{\mathrm{I}}$ (stress intensity factor), CTOD and J-integral (a value describing the energy state in the crack front zone), which are used depending on the nature of the crack. CTOD is an appropriate quantity to describe cracks of a mixed brittle and ductile nature [6-8].

Current regulations for the construction of ship hulls [9] and offshore structures [10] require a CTOD test to be performed in accordance with ISO 12135 [11] and ISO 15653 [12]. The regulations do not specify the particular type of specimens to be tested. This is a marked change from previously issued regulations. The offshore regulations [13], issued in 2011 but currently up to date, explicitly impose three-point bend specimens with $\mathrm{Bx} 2 \mathrm{~B}$ proportions, where $\mathrm{B}$ is the material thickness (see Fig. 1). The test is performed according to British Standards [14]. A similar situation occurred in a more recent edition of DNV offshore rules [15]. The regulations directly imposed the type and geometry of the specimen: three-point bended with proportions $\mathrm{Bx} 2 \mathrm{~B}$. The more recent edition of EEMUA 158 (Ammendment 5), of 2005 [16] also imposed the type of specimen: three-point bended $\mathrm{Bx} 2 \mathrm{~B}$ (preferred) or $\mathrm{BxB}$ (subsidiary). All of the cited regulations provide a single criterion value for CTOD. This may suggests that the CTOD value is independent of the type of specimen and, therefore, can be treated as a material constant. It is a well-known fact that at least four major factors influence the resulting value characterizing fracture toughness. These are: strain rate, element thickness, element dimension, and slit length in relation to the rest of the material. All factors are a function of temperature and affect the final course of the brittle transition curve [7][17]. The referenced standards [11], [14], [18] impose limitations and require records to identify the referenced factor, so tests performed based on them are comparable.

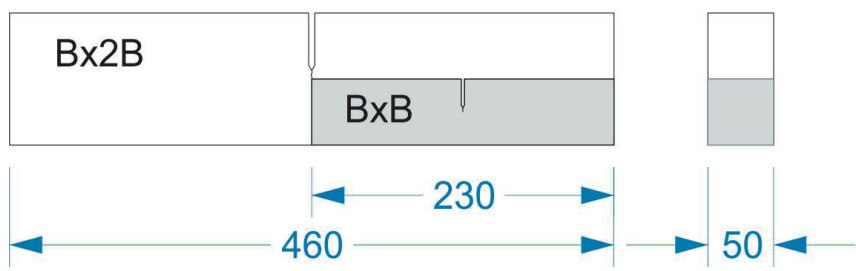

Fig. 1. Comparison of $B \times 2 B$ (white) and $B \times B$ (grey) specimen size. Both types of specimen are suitable for plate thickness of $50 \mathrm{~mm}$
Fig. 1 shows specimens Bx2B (height to thickness of specimen ratio equal to two) and $\mathrm{BxB}$ (height to thickness of specimen ratio equal to one) specific to a $50 \mathrm{~mm}$ thick plate. It can be clearly seen that the sample with dimensions $\mathrm{BxB}$ is definitely smaller. Detailed comparison of the dimensions and masses of samples of both types are presented in Table 1. Tab. 1. Comparison of $B x B v s B \times 2 B$ specimen dimension and masses [11], [14], [18]

\begin{tabular}{|l|c|c|c|}
\hline & $\begin{array}{c}\text { Symbol, } \\
\text { unit }\end{array}$ & $\begin{array}{c}\text { Value } \\
\text { for BxB } \\
\text { specimen }\end{array}$ & $\begin{array}{c}\text { Value } \\
\text { for Bx2B } \\
\text { specimen }\end{array}$ \\
\hline Width & $\mathrm{B}, \mathrm{mm}$ & 50 & 50 \\
\hline Height & $\mathrm{W}, \mathrm{mm}$ & 50 & 100 \\
\hline Span & $\mathrm{S}, \mathrm{mm}$ & 200 & 400 \\
\hline Total length & $\mathrm{L}, \mathrm{mm}$ & 230 & 460 \\
\hline Mass (steel for shipbuilding) &,$- \mathrm{kg}$ & $\sim 4.5$ & $\sim 18.1$ \\
\hline
\end{tabular}

In addition to the smaller size, the specimen also requires a machine with a smaller load capacity. A comparison of the required forces for specimens $\mathrm{BxB}(\mathrm{W}=\mathrm{B})$ and $\mathrm{B} \times 2 \mathrm{~B}$ $(\mathrm{W}=2 \mathrm{~B})$, for $50 \mathrm{~mm}$ thick shipbuilding steel, with ultimate strength of $537 \mathrm{~N} / \mathrm{mm}^{2}$ is summarised in Table 2. The relative crack length $\mathrm{a}_{0} / \mathrm{W}=0.5[-]$ was used for the calculations, where $\mathrm{a}_{0}$ is the relative, averaged, initial crack length.

Table 2. Comparison of requested force for $B \times B$ and $B \times 2 B$ specimens

\begin{tabular}{|l|c|c|}
\hline & $\begin{array}{c}\text { BxB } \\
\text { specimen } \\
\text { type }\end{array}$ & $\begin{array}{c}\text { Bx2B } \\
\text { specimen } \\
\text { type }\end{array}$ \\
\hline Required force in acc. to BS [14], kN & 111.9 & 224.0 \\
\hline Required force in acc. to ISO [11], kN & 134.3 & 238.5 \\
\hline
\end{tabular}

From the numerical data shown in Table 1 and Table 2, it is clear that the testing of sheet metal of the same thickness, carried out with $\mathrm{BxB}$ specimens will be easier than with $\mathrm{Bx} 2 \mathrm{~B}$ specimens. The purpose of the presented research, is to determine the effect of using a $\mathrm{BxB}$ specimen on the result obtained, in relation to a $\mathrm{B} \times 2 \mathrm{~B}$ specimen.

\section{RESEARCH METHODOLOGY}

The research work conducted consisted of stages. The first was to determine the mechanical properties of the tested material. Based on these, a numerical model of the material used for testing was created. The material model was implemented into a numerical three-point bending test. As a result, the force vs CMOD (Crack Mouth Opening Displacement) plots were obtained. From the obtained graph, the point value of CTOD was calculated. Eq. (1) (based on [11] and [14]) was used. Other standards, for example [18], have given other equations for calculating CTOD. There are also continuous attempts to improve the existing equations, e.g. [19-20]. Thus, it should be concluded that the quantity known as CTOD has undergone an evolution since its publication by Wells [21] in the early 1960s. 
$\delta_{0}=\left[\frac{S}{W} \cdot \frac{F}{\left(B B_{N} W\right)^{0.5}} \cdot g_{1}\left(\frac{a_{0}}{W}\right)\right]^{2} \cdot \frac{1-v^{2}}{2 R_{p 0.2} E}+\frac{0.4(W-a 0)}{0.6 a_{0}+0.4 W+Z} \cdot V_{P}$

where: $\delta_{0}-$ CTOD, uncorrected for stable crack extension, $\mathrm{mm} ; \mathrm{S}$ - support span of the specimen, $\mathrm{mm}$; W - specimen width, $\mathrm{mm}$; F - force, N; B - specimen thickness (equal to plate thickness), $\mathrm{mm} ; \mathrm{B}_{\mathrm{N}}-$ specimen net thickness between side grooves (in this case $B_{N}=B$ ), $m m ; g_{1}\left(a_{0} / W\right)$ - function concerning relative crack length, [-]; $v$ - Poisson's ratio, [-]; $\mathrm{R}_{\mathrm{p} 0.2}$ - proof strength for $0.2 \%$ of plastic elongation, $\mathrm{N} / \mathrm{mm}^{2}$; $\mathrm{E}$ - modulus of elasticity, $\mathrm{N} / \mathrm{mm}^{2} ; \mathrm{a}_{0}$ - initial crack length, $\mathrm{mm} ; \mathrm{V}_{\mathrm{P}}$ - plastic component of notch opening displacement, $\mathrm{mm} ; \mathrm{z}$ - the initial distance of the notch opening gauge measurement position from the notched edge of the specimen (in this case $\mathrm{z}=0$ ), $\mathrm{mm}$.

To validate the FEA (Finite Element Analysis) results, selected CMOD-force plots and calculated CTOD values were compared with experimental results. The effect of different relative crack length on CTOD was considered in the calculation plan. As the author's experience shows, it is significant [22].

\section{OBJECT OF INVESTIGATION}

The test object is VL E36 hull steel (according to DNVGL PT.2 CH2 SEC.1:2016) with a nominal thickness of $50 \mathrm{~mm}$. Table 3 gives the chemical composition of the tested steel, based on the material certificate.

Tab. 3. Chemical composition of tested steel

\begin{tabular}{|l|l|l|l|l|l|l|}
\hline $\mathrm{C}$ & $\mathrm{Si}$ & $\mathrm{Mn}$ & $\mathrm{P}$ & $\mathrm{S}$ & $\mathrm{Al}$ & $\mathrm{Nb}$ \\
\hline 0.161 & 0.46 & 1.50 & 0.012 & 0.002 & 0.031 & 0.042 \\
\hline $\mathrm{V}$ & $\mathrm{Ti}$ & $\mathrm{Cu}$ & $\mathrm{Cr}$ & $\mathrm{Ni}$ & $\mathrm{Mo}$ & $\mathrm{Ca}$ \\
\hline 0.052 & 0.005 & 0.016 & 0.05 & 0.04 & 0.006 & 0.002 \\
\hline
\end{tabular}

Mechanical properties were determined by in-house testing on an upgraded $\mathrm{ZD}-40 \mathrm{Pu}$ machine (force measurement accuracy $\pm 1 \%$ of the measured value). Elongation was measured using an Epsilon 2543-050M-025M-ST extensometer with a $50 \mathrm{~mm}$ measuring base. The extensometer allowed measurement up to the point of specimen rupture, with an accuracy of $\pm 0.001 \mathrm{~mm}$. Specimens with a circular crosssection, $10 \pm 0.1 \mathrm{~mm}$ in diameter, were used for the test. The specimen was tensioned with a strain rate $\dot{\varepsilon}=0.0044 \mathrm{1} / \mathrm{s}$. A photograph of the specimen during the tensile test is shown in Fig. 2. The specified mechanical properties of the tested steel are summarised in Table 4 . The properties were determined in accordance with the ISO standard [23].

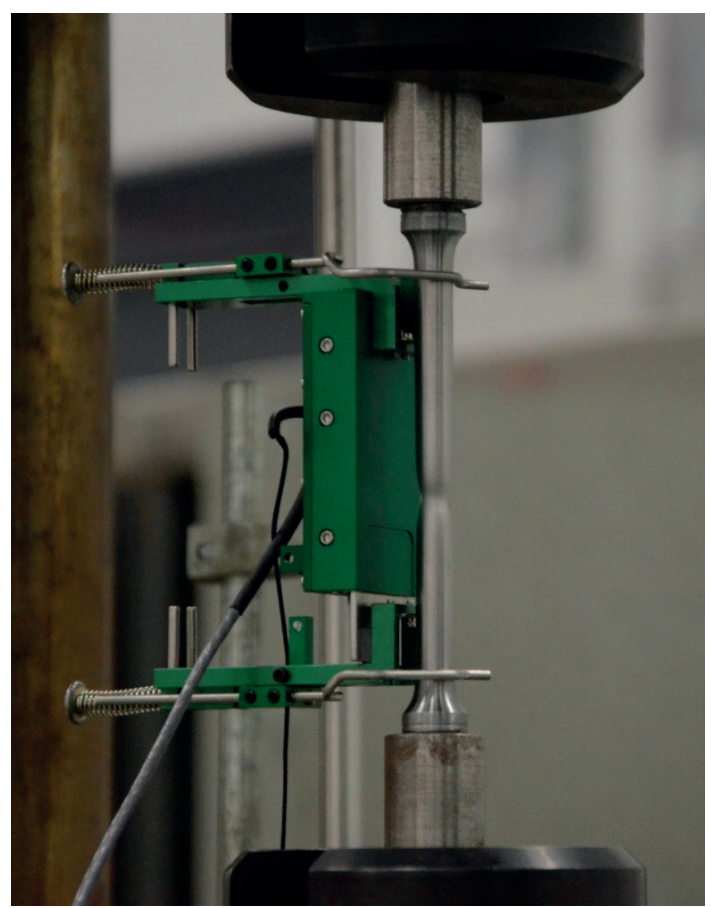

Fig. 2. Specimen during tension test. Moment of necking can be observed

Tab. 4. Summary of mechanical properties

\begin{tabular}{|c|c|c|c|c|}
\hline 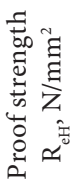 & 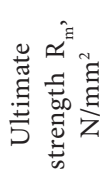 & 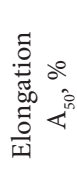 & 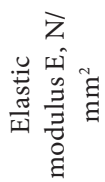 & 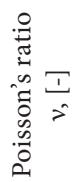 \\
\hline 398 & 537 & 29 & $2.15 \mathrm{e} 5$ & 0.3 \\
\hline
\end{tabular}

Fig. 3 shows the stress - strain plot obtained from the test (nominal characteristic, blue line). The actual plastic characteristic, further used for the numerical model, is also shown in the figure, as a red line. Extrapolation beyond $\mathrm{R}_{\mathrm{m}}$ was carried out based on Hollomon's formula [24].

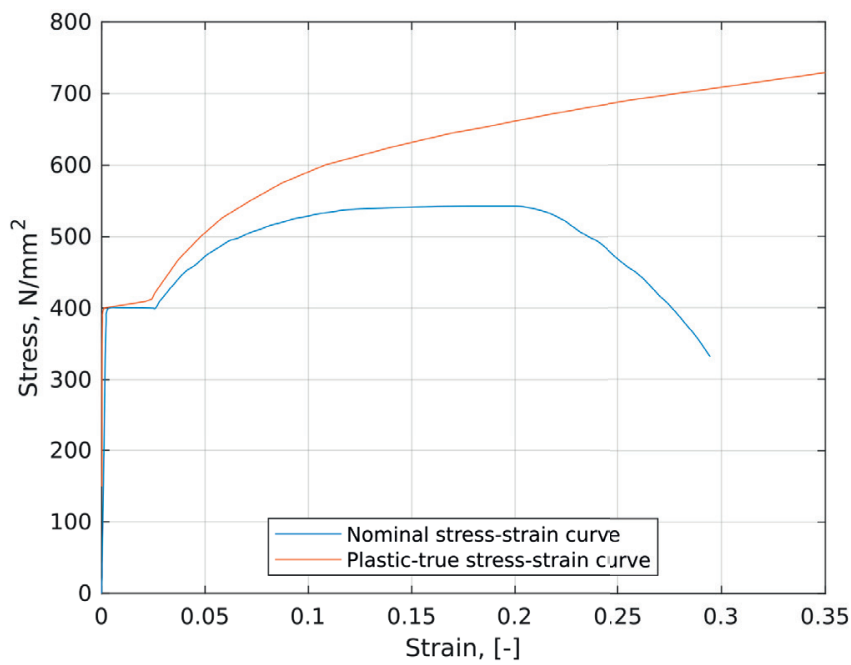

Fig. 3. Stress strain curves: nominal (blue), utilized in FE model (red) 


\section{FINITE ELEMENT ANALYSIS}

Numerical simulations were performed using Abaqus CAE 2019 software, using the explicit method. A validated elastic-plastic model of the material was used for the tests, following the procedure described in [25]. Due to the large deformations, the real characteristics (see Fig. 3), determined assuming a constant volume of the material during necking, were determined and applied to the numerical tests. The Huber-Misses-Hancke plastic strengthening model was adopted. The material model adopted included necking and a phenomenological model of material degradation based on a linear curve softening relationship as a function of strain increment. The model described by [26] was used. The case of ductile damage was considered and the model depended on 3 parameters: stress triaxiality (defined in Eq. (2)), plastic elongation and strain rate.

$$
\eta=\frac{-p}{q}
$$

where:

$\mathrm{p}, \mathrm{N} / \mathrm{mm}^{2}$ - hydrostatic pressure in the material defined as (3):

$$
p=\frac{-1}{3}\left(\sigma_{1}+\sigma_{2}+\sigma_{3}\right)
$$

$\mathrm{q}, \mathrm{N} / \mathrm{mm}^{2}$ - equivalent stress defined as (4):

$$
q=\frac{1}{\sqrt{2}} \sqrt{\left(\sigma_{1}-\sigma_{2}\right)^{2}+\left(\sigma_{2}-\sigma_{3}\right)^{2}+\left(\sigma_{3}-\sigma_{1}\right)^{2}}
$$

$\sigma_{1}, \sigma_{2}, \sigma_{3}-$ principal stress, $\mathrm{N} / \mathrm{mm}^{2}$

The model assumed that the onset of material degradation occurred at a value of $\eta \geq 0.33[-]$ and a plastic strain (failure strain) greater than 0.1605 [-]. These values were determined from the tensile test results and, similar to Bao and Wierzbicki [26], using the trial and error method. Since the CTOD test was quasistatic (performed at the same speed each time), the strain rate for which the $\eta$ and failure strain values were given was set at the level from the tensile test. In the crack region, elements with a size of $0.5 \mathrm{~mm}$ were used, which is a compromise between the relatively fast computational run (10 - $15 \mathrm{~h}$, depending on the model) and the agreeing force - CMOD curve with the laboratory results.

In order to reduce the computational model and time of computation, the planes of symmetry were used. The model was reduced to $1 / 4$, through appropriate boundary conditions. In the laboratory test, the load was transferred to the specimen through a $50 \mathrm{~mm}$ diameter bending mandrel. The former was modelled directly and the load was exerted by moving the bending mandrel along the $\mathrm{Y}$ axis. The roll supporting the model, which in reality has the possibility of rotation and movement, was reduced to half and supported through an elastic element with stiffness $\mathrm{K}=4500 \mathrm{~N} / \mathrm{mm}$. The idea of the FE model is presented in Fig. 4.

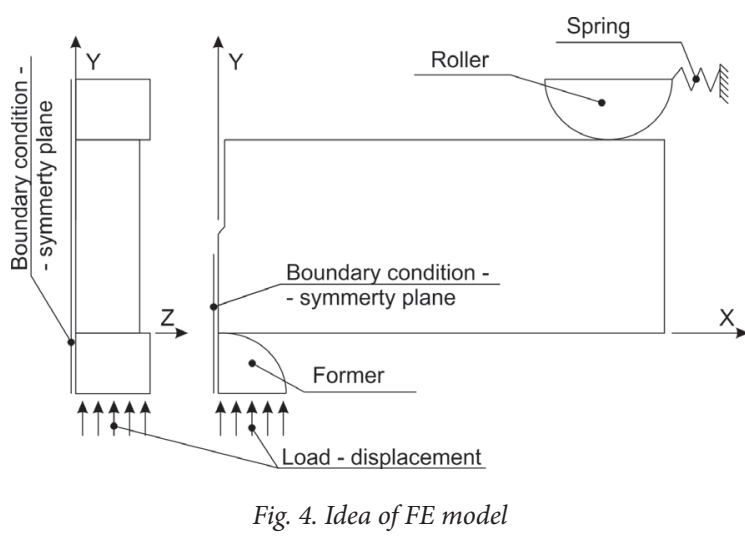

The spring stiffness was selected based on the measurement of the actual roll displacement made during laboratory testing. A hard, frictionless contact was used between the elements [27]. FE models for $\mathrm{BxB}$ and $\mathrm{Bx} 2 \mathrm{~B}$, with mesh refinement in the crack tip zone, are presented as Fig. 5 a) and 5 b).
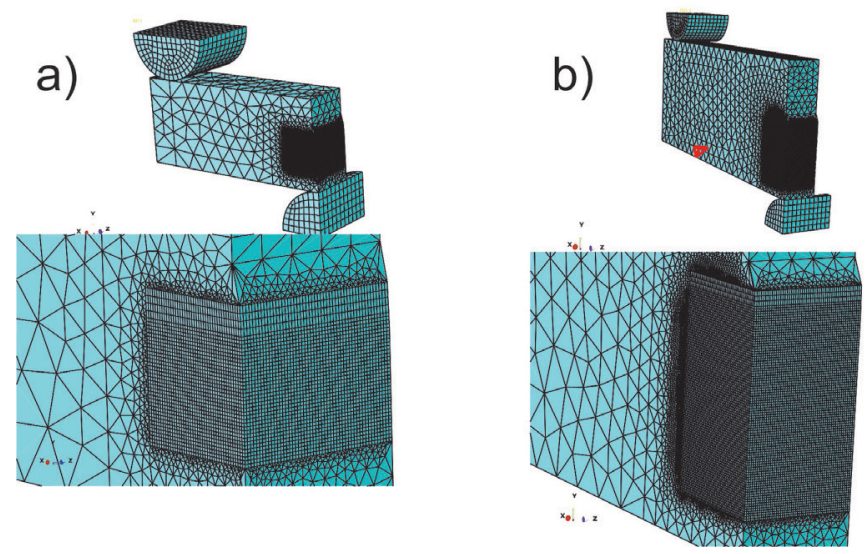

Fig. 5. FE model. Mesh refinement in crack tip zone can be seen; a) BxB specimen; b) Bx2B specimen

The primary evaluable output of the FEA was the force CMOD plots. The force was calculated as the sum of the nodal reactions in the $\mathrm{Y}$ direction (see Fig. 4). The reaction from the lower plane of the former was summed. The force reading location was exactly the same as in the laboratory tests (there is a force gauge under the mandrel), so the force from the FE model and the laboratory tests could be compared directly. CMOD was calculated as a displacement along the $\mathrm{X}$ axis. The displacement was read from a node in the symmetry axis of the specimen, on the top plane, at the edge of the notch. As with force, the location of the CMOD measurement coincided with the physical measurement in the laboratory.

\section{EXPERIMENTAL VALIDATION OF FINITE ELEMENT ANALYSIS}

Tests verifying the results obtained by FEM simulation were carried out on a digitally controlled $250 \mathrm{kN}$ test stand (force measurement accuracy $\pm 1 \%$ ). Displacement load was 
applied and the force value was the resultant. The CMOD was measured using an Epsilon 3541-010M-120M-LT extensometer with an $8-\mathrm{mm}$ measurement base and a range of $-2 \mathrm{~mm}$ to $12 \mathrm{~mm}$. The accuracy of the extensometer, as determined by the calibration certificate, is $\pm 0.5 \%$. The specimen during the CTOD test, is shown in Fig. 6.

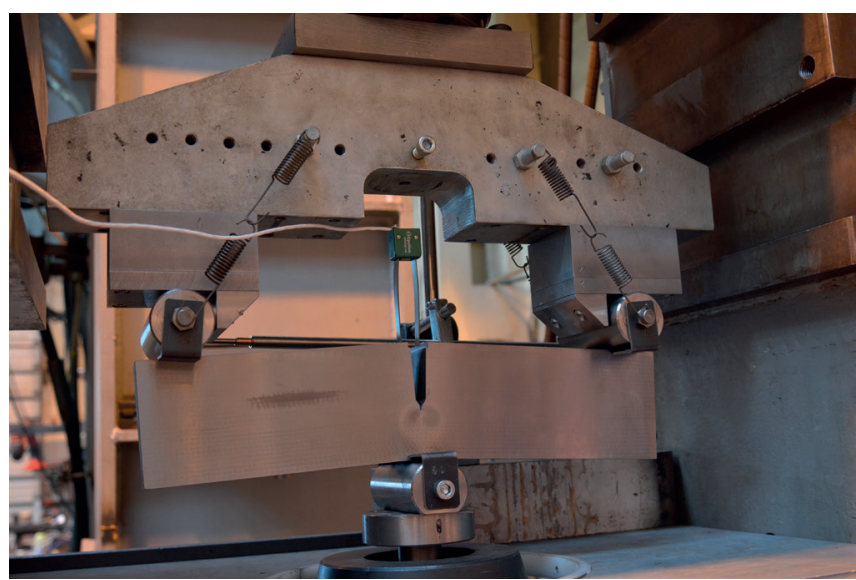

Fig. 6. CTOD test stand

As mentioned above, an additional measurement to that performed according to the standards, was the offset of the support roll. HBM WA100 load cells were used with a resolution of $0.01 \mathrm{~mm}$. All of the test parameters (including those from the controller of testing system) were recorded using the HBM QuantumX MX 840A Data Acquisition System, with Catman software. This provided a common timebase for all recorded parameters, which greatly facilitated further analysis of the laboratory test results.

\section{RESULTS OF THE RESEARCH}

The results are CTOD values for both types of specimens, taking into account the different relative crack lengths $\mathrm{a}_{0} / \mathrm{W}$ [-]. The basis of the calculation of CTOD values, following from Eq. (1) and the geometric values, are the maximum force and the plastic component of CMOD $-\mathrm{V}_{\mathrm{p}}, \mathrm{mm}$. Both of these values were read from the force vs CMOD curves and then substituted into Eq. (1). The selected force vs CMOD curves obtained from FEA are shown in Fig. 7. Solid lines indicate curves for specimen type $\mathrm{BxB}$, while dashed lines indicate $\mathrm{Bx} 2 \mathrm{~B}$. It is clearly seen, as expected, that the specimens with larger cross-sections (and thus span) require significantly higher force. For $\mathrm{BxB}$ specimens with $\mathrm{a}_{0} / \mathrm{W}=0.5$, the maximum force was $130.7 \mathrm{kN}$ while, for $\mathrm{Bx} 2 \mathrm{~B}$ specimens with the same relative crack length it was $218.3 \mathrm{kN}$. Similarly, for relative crack length $\mathrm{a}_{0} / \mathrm{W}=0.6$, specimen $\mathrm{BxB}$ required $56.6 \mathrm{kN}$, while specimen $\mathrm{Bx} 2 \mathrm{~B}$ required $87.8 \mathrm{kN}$. Thus, specimen $\mathrm{Bx} 2 \mathrm{~B}$ required 1.67 times more force compared to specimen $\mathrm{BxB}$, in the first case, and 1.55 times in the second case.

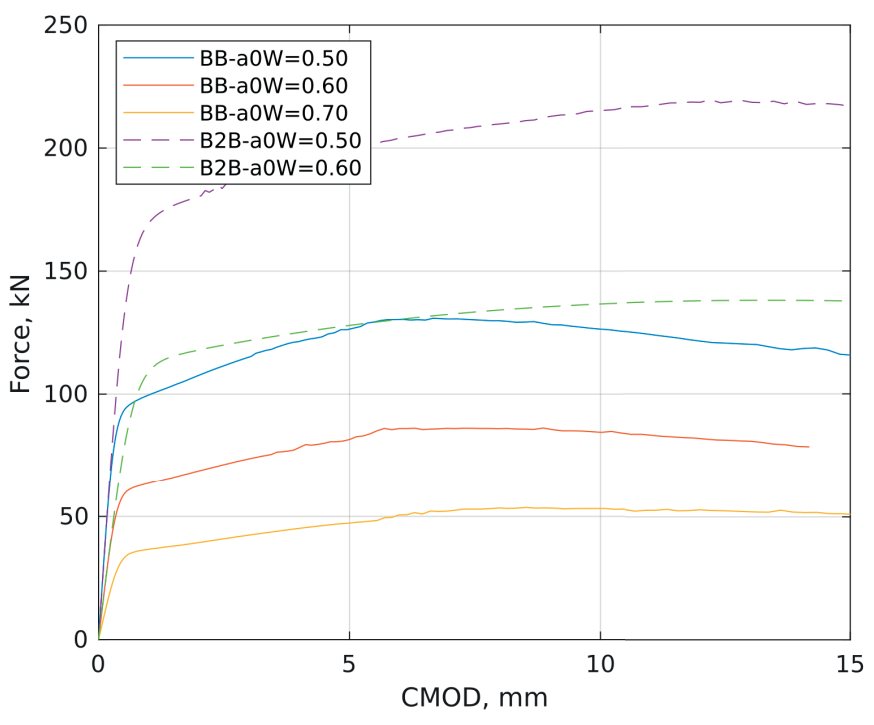

Fig. 7. Chosen force vs CMOD curves obtained in FEA

Fig. 8 shows the comparison of force vs CMOD curves for numerical tests (dashed lines) and laboratory tests (solid lines). Laboratory tests were performed for specimens $\mathrm{Bx} 2 \mathrm{~B}$ and two relative gap lengths, $\mathrm{a}_{0} / \mathrm{W}=0.5[-]$ and $\mathrm{a}_{0} / \mathrm{W}=0.6[-]$.

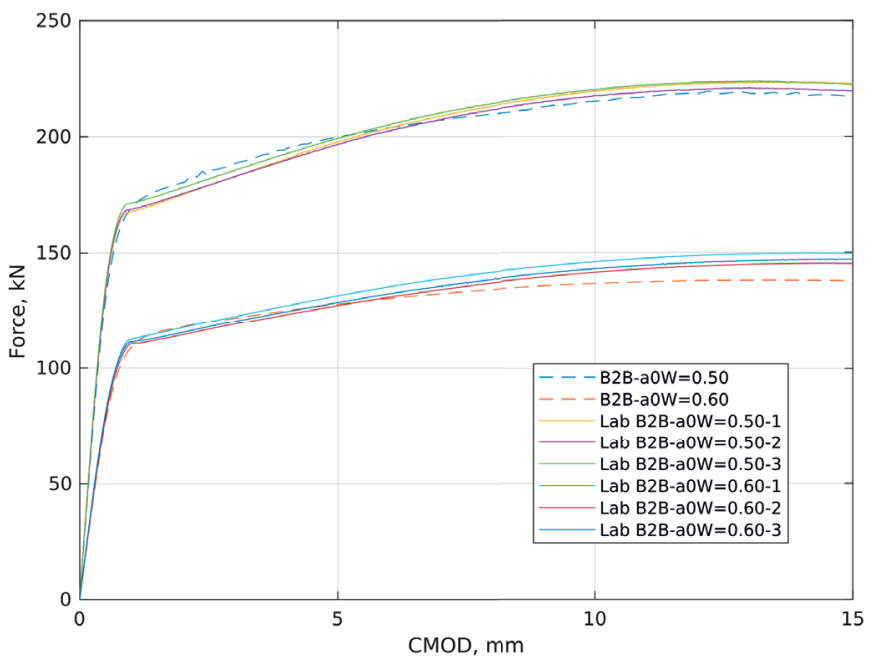

Fig. 8. Comparison of force vs CMOD curves from FEA and laboratory experiments

Fig. 8 shows a good convergence of the force, run as a function of CMOD, especially for $\mathrm{a}_{0} / \mathrm{W}=0.5[-]$. For $\mathrm{a}_{0} / \mathrm{W}=0.6[-]$, the curves obtained by laboratory testing are above the curve obtained by numerical calculation. This is due to the peculiarities of conducting laboratory tests, particularly the fact that in laboratory tests it is not possible to control $\mathrm{a}_{0} / \mathrm{W}$ accurately before testing. The magnitude of $\mathrm{a}_{0}$ is determined after the CTOD testing is finished. The laboratory-determined curves presented are for $\mathrm{a}_{0} / \mathrm{W}$ of around 0.59 to $0.60[-]$, which explains the fact that they lie above the numerically obtained curve in the graph. 
Fig. 9 shows the calculated CTOD values for samples $B \times B$ (blue asterisk) and $\mathrm{Bx} 2 \mathrm{~B}$ (red caro) as a function of $\mathrm{a}_{0} / \mathrm{W}$. The results of laboratory tests (black stars) are also marked in the figure. Calculations were performed for the $\mathrm{a}_{0} / \mathrm{W}$ range from 0.45 to 0.70 [-]. The adopted range is dictated by the limitations arising from the ISO standard, Eq. (1) is valid for such a $\mathrm{a}_{0} / \mathrm{W}$ range.

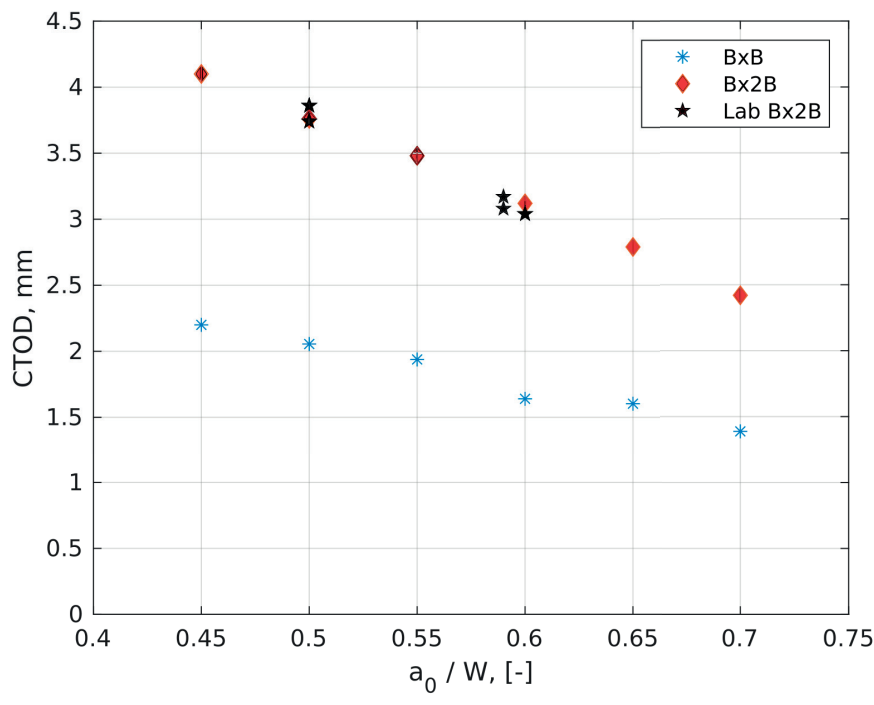

Fig. 9. CTOD values calculated for $B \times B$ and $B \times 2 B$, as a function of $a_{d} / W$

\section{SUMMARY}

The presented results clearly show the significant effect of specimen cross-section geometry on CTOD. The yields obtained on $\mathrm{BxB}$ type specimens are clearly lower than for Bx2B type specimens. Thus, regulatory bodies, such as classification societies, should set different criterion values depending on the specimen type used.

A significant effect of relative crack length $\mathrm{a}_{0} / \mathrm{W}$ on CTOD value was observed for both of the cases studied. In both cases, it is linear. For BxB specimens it is significantly smaller than for specimens with a $\mathrm{Bx} 2 \mathrm{~B}$ cross-sectional ratio.

It follows from the above that, for elastic-plastic fracture mechanics, the CTOD results obtained cannot be treated as material constants - their values depend on the type of specimen used, how it is loaded and the relative crack length. In case of ductile fracture (current one), there is also the phenomenon of the crack length increase during the test. Since an increase in crack length decreases CTOD, the values that take stable tearing into account will be lower than the uncorrected values as presented in this paper. The adopted numerical model should be developed in the future and allow the gap growth to be measured during the numerical simulation. The developed model will require additional validation tests performed in the laboratory.

\section{ACKNOWLEDGEMENTS}

Computing in Abaqus software, presented in this paper, were carried out within research grant. Calculations were carried out at the Centre of Informatics Tricity Academic Supercomputer \& Network.

\section{REFERENCES}

1. K. Sun, Y. Hu, Y. Shi, and B. Liao, 'Microstructure Evolution and Mechanical Properties of Underwater Dry Welded Metal of High Strength Steel Q690E Under Different Water Depths,' Polish Marit. Res., vol. 27, no. 4, pp. 112-119, Dec. 2020, doi: 10.2478/pomr-2020-0071.

2. J. Kowalski, Ł. Licznerski, M. Supernak-Marczewska, and K. Emilianowicz, 'Influence of Process of Straightening Ship Hull Structure Made of 316L Stainless Steel on Corrosion Resistance and Mechanical Properties,' Polish Marit. Res., vol. 27, no. 4, pp. 103-111, Dec. 2020, doi: 10.2478/pomr-2020-0070.

3. X. Li, Z. Zhu, Y. Li, and Z. Hu, 'Design and Mechanical Analysis of a Composite T-Type Connection Structure for Marine Structures,' Polish Marit. Res., vol. 27, no. 2, pp. 145-157, Jun. 2020, doi: 10.2478/pomr-2020-0036.

4. K. Woloszyk, Y. Garbatov, J. Kowalski, and L. Samson, 'Experimental and Numerical Investigations of Ultimate Strength of Imperfect Stiffened Plates of Different Slenderness,' Polish Marit. Res., vol. 27, no. 4, pp. 120-129, Dec. 2020, doi: 10.2478/pomr-2020-0072.

5. Y. Zilin, W. Yu, Y. Xuefeng, G. Anping, Z. Rong, and J. Yanjie, 'Investigations of Mechanical Properties of API P110 Steel Casing Tubes Operated in Deep-Sea Sour Condensate Well Conditions,' Polish Marit. Res., vol. 27, no. 3, pp. 121129, Sep. 2020, doi: 10.2478/pomr-2020-0053.

6. A. Neimitz, Mechanika Pękania. Warszawa: Wydawnictwo Naukowe PWN, 1998.

7. F. C. Campbell, Fatigue and Fracture: Understanding the Basics. 2012.

8. W. Dahl and P. Langenberg, 'Fracture Toughness of Metallic Materials,' in Encyclopaedia of Materials: Science and Technology (Second Edition), 2001, pp. 3336-3340.

9. Polski Rejestr Statków, Rules For Classification and Construction on sea-going ships, Part IX, Materials and Welding. Gdańsk: PRS, 2021.

10. DNV, DNV OFFSHORE STANDARDS, DNV-OS-B101, Metallic materials. DNV AV, 2021. 
11. ISO, ISO 12135:2016 Metallic materials - Unified method of test for the determination of quasistatic fracture toughness. Geneva, 2016.

12. ISO, Metallic materials - Method of test for the determination of quasistatic fracture toughness of welds (ISO 15653:2018). Geneva: ISO, 2018.

13. Standards Norway, NORSOK STANDARD M-101, Structural steel fabrication, 5th ed. Lysaker, 2011.

14. BSI, BS 7448-1:1991 - Fracture mechanics toughness tests. Method for determination of KIC, critical CTOD and critical J values of metallic materials. London: BSI, 1991.

15. Det Norske Veritas (DNV), 'DNV-OS-C401 Fabrication and Testing of Offshore Structures,' no. October, 2014.

16. The Engineering Equipment and Materials Users' Association, Construction Specification for Fixed Offshore Structures in the North Sea, Publication No. 158 (1994 Edition), Amendment No, 4, . EEMUA, 2005.

17. T. Meshii, K. Lu, and R. Takamura, 'A failure criterion to explain the test specimen thickness effect on fracture toughness in the transition temperature region,' Eng. Fract. Mech., vol. 104, pp. 184-197, 2013, doi: 10.1016/j. engfracmech.2013.03.025.

18. ASTM International, 'ASTM E1820 - 18a Standard Test Method for Measurement of Fracture Toughness,'2018.

19. T. Kawabata, T. Tagawa, T. Sakimoto, Y. Kayamori, M. Ohata, Y. Yamashita, E. Tamura, H. Yoshinari, S. Aihara, F. Minami, H. Mimura, Y. Hagihara 'Proposal for a new CTOD calculation formula,' Eng. Fract. Mech., vol. 159, pp. 16-34, 2016, doi: 10.1016/j.engfracmech.2016.03.019.

20. T. Kawabata T. Tagawa, Y. Kayamori, M. Ohata, Y Yamashita, M Kinefuchi, H. Yoshinari, S. Aihara, F. Minami, H, Mimura, Y. Hagihara, 'Applicability of new CTOD calculation formula to various a0/W conditions and $\mathrm{B} \times \mathrm{B}$ configuration,' Eng. Fract. Mech., vol. 179, pp. 375-390, 2017, doi: 10.1016/j.engfracmech.2017.03.027.

21. [21] A. Wells, 'Application of fracture mechanics at and beyond general yield, Report No.

M13/63,'Br.Weld.

J., pp. 563-590, 1963.

22. J. Kowalski and J. Kozak, 'The Effect of Notch Depth on CTOD Values in Fracture Tests of Structural Steel Elements,' Polish Marit. Res., vol. 25, no. 2, pp. 85-91, 2018, doi: 10.2478/pomr-2018-0058.

23. ISO, ISO 6892-1:2016 Metallic materials - Tensile testing - Part 1: Method of test at room temperature. Geneva, 2016.
24. H. Hollomon, 'Tensile deformation.' Aime Trans, vol. 12, no. (4), pp. 1-22, 1945.

25. J. Kowalski and J. Kozak, 'Numerical Model of Plastic Destruction of Thick Steel Structural Elements,' Polish Marit. Res., vol. 25, no. 2, pp. 78-84, 2018, doi: 10.2478/ pomr-2018-0057.

26. Y. Bao and T. Wierzbicki, 'A comparative study on various ductile crack formation criteria,' J. Eng. Mater. Technol. Trans. ASME, vol. 126, no. 3, pp. 314-324, 2004, d o i : $10.1115 / 1.1755244$.

27. Dassault Systems, Abaqus 2019 Documentation. Providence: Dassault Systèmes,

\section{CONTACT WITH THE AUTHOR}

\section{Jakub Kowalski}

e-mail: jakkowal1@pg.edu.pl

Gdansk University of Technology,

Narutowicza 11/12

80-233 Gdańsk

Poland 